\title{
Hypogonadism in young men treated for cancer
}

\author{
Aleksander Giwercman ${ }^{1}$, Yvonne Lundberg Giwercman ${ }^{2}$ \\ ${ }^{1}$ Molecular Reproduction, ${ }^{2}$ Molecular Genetic Reproduction, Department of Translational Medicine, Lund University, \\ Malmö, Sweden
}

\begin{abstract}
An ever-increasing proportion of young males treated for cancer are cured. Therefore, one of the major challenges of modern Clinical Oncology is to ensure good quality of life. Cancer disease per se as well as cancer treatment may have a negative impact on androgen production, thereby leading to subclinical or clinically overt hypogonadism. Since the symptoms of androgen deficiency are rather unspecific, it is important that reproductive hormone levels be checked in young men who have been treated for cancer. As androgen deficiency in men is associated with increased long-term risk of osteoporosis as well as cardiovascular and metabolic disease, those cancer survivors who present with signs of insufficient androgen production should be followed and preventive as well as therapeutic measures, including androgen replacement therapy, should be applied according to the current guidelines.
\end{abstract}

Key words: Cancer treatment, Childhood cancer, Hypogonadism, Leydig cell function, Testicular cancer, Testosterone

\section{INTRODUCTION}

Nowadays, thanks to greatly improved diagnostic procedures, efficient surgical and radiation techniques and effective chemotherapy, there are ever more young cancer survivors. This is true, for example, of those treated for such childhood cancers as testicular malignancy and lymphomas. On the other hand, both caner per se and different modalities of oncological treatment can be harmful to male reproductive function (Figure 1). In this context, so far most focus has been on impairment of fertility in young cancer survi-

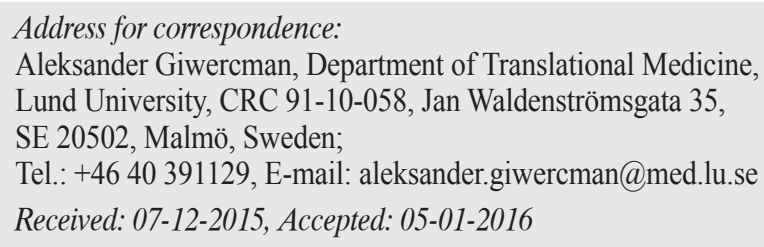

vors. ${ }^{1}$ However, there is a growing body of evidence indicating that these patients are at increased risk of developing both primary and secondary hypogonadism..$^{2-5}$ Testicular damage can be due to testicular disease, surgery of the gonads or radiation therapy directed to the testes and adjacent tissues, as well as to systemic chemotherapy. Secondary hypogonadism can be induced by surgery or radiotherapy of tumors in the central nervous system, foremost in the pituitary region. In addition, testosterone levels naturally decrease with age, and men who are eugonadal in early adulthood can develop androgen deficiency at a more advanced age. ${ }^{6,7}$

Testosterone deficiency implies an increased risk of developing osteoporosis, depression and disturbed metabolism, eventually leading to metabolic syndrome and type 2 diabetes, as well as cardiovascular 


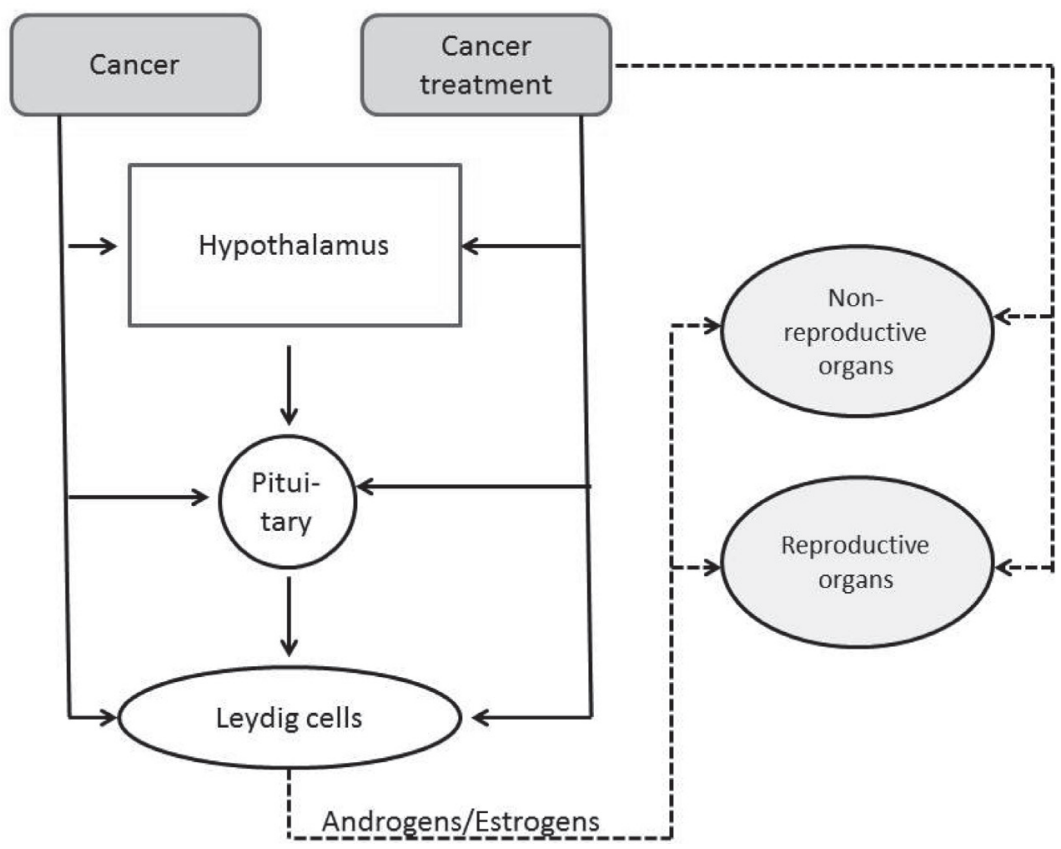

Figure 1. Possible mechanisms of action linking cancer and cancer treatment to impairment of function of reproductive and nonreproductive organs.

diseases ${ }^{8-10}$ Identifying men with hypogonadism can be difficult, since the symptoms are rather unspecific ${ }^{11}$ (Table 1). However, it is extremely important from a clinical point of view, given that long-term sequelae of androgen insufficiency can possibly be prevented by testosterone replacement. ${ }^{12,13}$

The aim of this review is to point out several highrisk groups among young men successfully treated for cancer. Furthermore, it will also provide some recommendations for routine follow-up of these men in order to discover early signs of hypogonadism and prevent its long-term complications.

\section{CANCER DIAGNOSES MOST COMMONLY ASSOCIATED WITH HYPOGONADISM RISK}

\section{Testicular cancer}

Testicular germ cell cancer (TGCC), although relatively rare, is the most common malignancy among males aged 20 to 40 years. For unknown reasons, the incidence of this disease has increased 3-4 fold during the last 5 decades, at least among Caucasians. ${ }^{14,15}$ Nevertheless, in parallel with the increased incidence, a significant improvement in survival rates has been achieved and today, in the best centers, more than $95 \%$ of TGCC patients are cured. ${ }^{16}$

Table 1. Symptoms associated with hypogonadism in adult men

\begin{tabular}{ll}
\hline Symptoms related to hypogonadism & More subtle symptoms associated with hypogonadism \\
\hline - Reduced or lack of libido & - Decreased energy and motivation \\
- Reduced incidence of spontaneous erections & - Difficulty in concentrating \\
- Gynecomastia & - Increased aggressiveness \\
- Reduced body hair and reduced need for shaving & - Dysthymia / depression \\
- Small, soft testes (volume $<5 \mathrm{ml}$ ) & - Normochromic normocytic anemia (Hb within the normal range for women) \\
- Reduced fertility & - Increased amount of subcutaneous and abdominal fat \\
- Osteopenia / osteoporosis & - Reduced working capacity, both physical and mental \\
- Decreased muscle mass and muscle strength & - Increased need for sleep and sleep problems \\
- Hot flushes and sweating & - Increased BMI \\
\hline
\end{tabular}


Long-term follow-up studies of TGCC survivors have shown that these men are at increased risk of adverse cardiovascular events as well as metabolic disease. ${ }^{17-19}$ Whether these diseases are fully or partially due to testosterone deficiency is so far unknown. However, there is no doubt that TGCC as such, as well as the therapy given, may constitute a hazard to reproductive function. ${ }^{5,20}$

\section{Impact of cancer}

There is a growing body of evidence indicating that TGCC arises in early fetal life, and it has been suggested that this malignancy is part of so-called Testicular Dysgenesis Syndrome (TDS), the other components being poor semen quality, cryptorchidism and hypospadias. ${ }^{21,22}$ According to the TDS hypothesis, the abnormal fetal germ cell development leading to TGCC is linked to Sertoli and Leydig cell insufficiency. For that reason, it is obvious to expect TGCC patients to be more prone to testosterone deficiency.

In accordance with this anticipation, it was found that Leydig cell response to hCG stimulation is significantly lower in men unilaterally orchiectomized due to TGCC, as compared to those in whom one testis was removed due to torsion or trauma. ${ }^{23}$ The few studies dealing with pre-orchiectomy hormonal levels in TGCC men have failed to find any increase in LH and/or decrease in testosterone levels in hCG-negative patients. ${ }^{24}$ However, in 33\% of these men the LH/T ratio was reported to be outside the $97.5^{\text {th }}$ percentile before orchiectomy, suggesting subtle disturbances of the pituitary-Leydig cell axis already present at the time of diagnosis. ${ }^{25}$

\section{Impact of cancer treatment and other risk factors}

Several risk factors of post-treatment hypogonadism have been identified, ${ }^{20,26,27}$ these including treatment intensity, pre-treatment hypogonadism, age, testicular microlithiasis.

Orchidectomy is standard treatment in men diagnosed with TGCC, a procedure that was reported not to be followed by immediate decline in testosterone levels. However, a significant increase in LH concentration indicates a reduction in Leydig cell capacity. ${ }^{28}$ Accordingly, long-term follow-up of TGCC men has shown a doubling in the prevalence of hypogonadism in patients treated with surgery only, as compared to controls. ${ }^{27}$
It seems that the risk of androgen deficiency increases with the intensity of the treatment, as almost $30 \%$ of 10 -year survivors given chemotherapy at doses above the standard treatment present with increased LH and/or subnormal testosterone levels. ${ }^{27}$ It also appears that although in some men standard doses of chemotherapy or retroperitoneal irradiation are likely to result in hypogonadism 6-12 months posttreatment, the endocrine parameters may be normalized subsequently. However, in the long term, even these men are at increased risk of testosterone deficiency. ${ }^{26}$

The risk of hypogonadism was found to be 1.5 times higher in TGCC survivors above 45 years as compared to those in younger age groups. This finding may be explained by the age-related deterioration of Leydig cell function. ${ }^{27}$

Finally, microlithiasis in the contralateral testis (TM), as detected with ultrasound, was found to be associated with 4-5 times increased risk of testosterone deficiency. This phenomenon may be explained by previous reports on a link between TDS and TM..$^{29,30}$

\section{Childhood cancer}

This group of patients encompasses a broad range of cancer diagnoses, considering both histological type and anatomical localization. They can be diagnosed in early postnatal life, during childhood and even at the time of or after the completion of puberty. Therefore, childhood cancer survivors (CCS) represent a very heterogeneous group for which only some general aspects regarding the impact of disease and its treatment on the risk of hypogonadism can be given. In any case, the survival rates for CCS are generally high, close to $75-80 \%$. Therefore, even in these latter patients the issue of long-term reproductive function is of the highest importance.

\section{Impact of cancer}

A small peak of testicular cancer incidence is seen during the first three years of life. After a lowincidence childhood period, the pubertal and early post-pubertal periods are characterized by increases in the incidence of TGCC. For the above patients, the considerations regarding the link between cancer per se and Leydig cell dysfunction are similar to those for adult patients, although early childhood cancer is not regarded as being part of TDS. Relatively rare 
tumors in the pituitary gland, hypothalamus or their vicinity may, through their expansive growth, have a negative impact on gonadotropin secretion and, thereby, lead to testosterone deficiency. ${ }^{31}$

\section{Impact of cancer treatment and other risk factors}

Considered as a group, CCS have a significantly increased risk of hypogonadism, defined as decreased testosterone and/or high LH. This hormonal aberration is found in approximately $25 \%$ of those who reach early adulthood. It corresponds to 5-7 times increased odds ratio for this adverse treatment outcome as compared to age-matched healthy controls. ${ }^{4}$

Hypophysectomy and testicular irradiation (e.g. as part of leukemia treatment or total body irradiation prior to bone marrow transplantation) are obvious reasons for secondary and primary hypogonadism, respectively. However, other types of treatment were found to increase the risk of testosterone deficiency: ${ }^{4}$

- Hypogonadism was seen in $20 \%$ of CCS following brain surgery (not close to the pituitary), whereas this effect was not observed in those receiving cranial irradiation. Furthermore, CCS treated with surgery alone (other than brain surgery) had no increased risk of developing hypogonadism.

- Increased odds ratio for hypogonadism was also seen in those treated with chemotherapy, either alone or in combination with (non-testicular) radiation therapy. Interestingly, although this risk increase was most pronounced in those men who have received alkylating drugs, usually considered as being most gonadotoxic, the adverse effect of chemotherapy was observed even for other types of treatment regimens.

Testicular size has been identified as a useful clinical marker of hypogonadism in adult CCS. When these men are grouped as per testicular volume, the proportion of those with hypogonadism in individuals with a total volume greater than $24 \mathrm{~mL}$ was $13 \%$ (odds ratio $\sim 3$ ), while in patients with a total volume of $24 \mathrm{~mL}$ or less, the proportion of hypogonadism was $58 \%$ (odds ratio $\sim 30$ ).

\section{Other cancer diagnoses}

In men, the lifetime risk of rectal cancer (RC) is about $2 \%$ and more than $60 \%$ of these men are expected to be cured. Preoperative radiotherapy is frequently applied in these men and, although the testes are usually outside the target radiation volume, they can be exposed to scattered irradiation and, in some cases, be directly exposed. The available data indicate approximately 3 times increased risk of subnormal testosterone levels in RC patients given irradiation as compared to those treated with surgery only. ${ }^{32,33}$

Another relatively large group of young cancer survivors, in whom the issue of Leydig cell dysfunction may become a clinical problem, are those with hematological malignancies. Following non-myeloablative bone marrow transplantation, sustained severe damage to the Leydig cells was observed. This effect was seen as a significant increase in LH levels (median LH pre-transplant: $5.4 \mathrm{IU} / \mathrm{L}$; median LH post-transplant: 9.6 IU/L) and reduced Leydig cell reserve, as evident from a diminished $\mathrm{T} / \mathrm{LH}$ ratio (2.6 pre-transplant vs. 1.6 post-transplant).$^{34}$ Even cytotoxic treatment was found to be deleterious only to Leydig cell function in lymphoma patients. Thus, $25 \%$ of men treated with COPP-regimen (cyclophosphamide, vincristin, procarbazine, prednisolone) had elevated LH levels and in as many as $90 \%$ the $\mathrm{GnRH}$-stimulated $\mathrm{LH}$ response was increased..$^{35}$ In a similar way, chemotherapy has an important impact on spermatogenesis, the treatment regimens not including alkylating drugs and/ or irradiation being less deleterious to testosterone production. $^{4}$

\section{CLINICAL CONSEQUENCES OF HYPOGONADISM}

Testosterone is a key regulator of male reproductive function but also exhibits significant effects in non-reproductive tissues. The classical symptoms of hypogonadism are listed in Table 1. During the past few decades, a number of studies have shown an association between hypogonadism and several serious clinical conditions. This information is briefly summarized below.

\section{Hypogonadism and sexual dysfunction}

Normal androgenic action is one of the prerequisites for normal sexual function. ${ }^{36,37}$ Low testosterone levels are associated with loss of libido and erectile dysfunction. Studies made in older men indicate that loss of libido may be registered already when total 
testosterone is at the low normal range, while truly subnormal testosterone concentrations are needed in order to cause erectile dysfunction i.e. in order to have erectile dysfunction testosteorne levels should be really low. ${ }^{38}$ Although, at least in men above the age of 40 years, sexual symptoms seem to be the best clinical markers of hypogonadism, ${ }^{37}$ it should be kept in mind that androgen deficiency is usually seen only in approximately $10 \%$ of men seeking medical advice due to erectile dysfunction. ${ }^{39}$ Sexual dysfunction observed in hypogonadal men may be due to direct effects of testosterone on the reproductive organs, but might also be mediated by its impact on brain function, as low hormone levels lead to disturbed sleep and depression.

\section{Hypogonadism, metabolic, cardiovascular and other systemic diseases}

Male hypogonadism is closely linked with obesity, decreased insulin sensitivity, dyslipidemia and endothelial dysfunction. ${ }^{40,41}$ Thus, it is not surprising that type 2 diabetes, metabolic syndrome and atherosclerosis are overrepresented among men with low testosterone levels. It is, however, still a matter of discussion whether testosterone deficiency is a cause or a consequence of these cardiovascular and/or metabolic disturbances. It seems that both scenarios are plausible. A negative association between total testosterone and the risk of developing autoimmune disease, such as rheumatoid arthritis, has also been reported. ${ }^{42}$ This may be due to the well-known antiinflammatory effect of the male sex hormone. ${ }^{43,44}$

\section{Hypogonadism and osteoporosis}

Osteoporosis is less frequently observed among older men as compared to older women. ${ }^{45}$ This is probably due to the absence of a sharp age-related decline in sex hormone production in males. However, androgen deficiency does indeed lead to lower bone mineral density and thereby increased risk of osteoporosis. Although a degree of direct impact of testosterone on bone mineralization has been shown, ${ }^{46-49}$ most of the androgenic effects on the bone are mediated through the estrogens to which the male sex hormone is converted through the action of aromatase.

Increased risk of cardiovascular and metabolic disease, as well as of osteoporosis, has been reported in young male cancer survivors, most studies focusing on TGCC, the most common malignancy in young males. The risk of the above long-term complications seems to be positively associated with the level of intensity of cancer treatment. ${ }^{17-19}$ Whether the latter is caused by hypogonadism, which is more frequent in these patients as compared to the background population, is not yet known. However, low testosterone levels were reported as a marker of not only increased morbidity but also of mortality. ${ }^{50,51}$

\section{CLINICAL GUIDELINES}

\section{At cancer diagnosis}

\section{Pre-pubertal boys}

Apart from the first 3-6 months after birth, Leydig cells are inactive until puberty. Therefore, there is no possibility of assessing the pre-cancer treatment status of testicular endocrine function in these subjects. Furthermore, apart from shielding the testes to avoid scattered irradiation of the gonads, there are no means of protecting the Leydig cells from the potential harmful effects of cancer therapy.

\section{Post-pubertal men}

These patients will typically be referred for semen cryopreservation. In such a case, the status of Leydig cell function should be assessed in order to be able to detect possible deterioration attributable to treatment. Hormone analyses should include serum levels of total testosterone, LH, SHBG and estradiol (optional). Blood sampling should be performed between 8 and $10 \mathrm{am} .{ }^{52}$ In TGCC patients, the ultrasonographic appearance of microcalcifications in the contralateral testicle should be examined, since it can predispose for post-treatment hypogonadism.

\section{After cancer treatment}

\section{Pre-pubertal boys}

These patients should be carefully followed for signs of delayed puberty.

\section{Post-pubertal men}

Men treated for cancer in childhood or adulthood should be offered investigation aiming to disclose any signs of androgen deficiency as a part of regular follow-up. In childhood cancer survivors, this should 
be done after completion of puberty. In the case of malignancy recurring during adulthood, the diagnostic work-up should be carried out 6-12 months following the completion of chemotherapy. The onset of hypogonadism should be expected immediately after several procedures including bilateral orchidectomy or hypophysectomy and/or radiotherapy to the testes or the pituitary gland. Apart from these cases, the symptoms of male hypogonadism, which are rather unspecific, can develop slowly and gradually. Therefore, the symptoms may be overlooked by the patient as well as by a doctor not specifically focusing on the possibility of androgen deficiency.

Diagnosis of androgen deficiency in adult patients previously treated for cancer is based on the traditional criteria for male hypogonadism:

- Symptoms of androgen deficiency in males (see Table 1)

- Low serum testosterone $(<12 \mathrm{nmol} / \mathrm{L}$ or significantly lower than pre-treatment) and/or

- High serum LH (>10 IU/L) (not applicable if secondary hypogonadism is suspected).

If the patient has no clear symptoms of hypogonadism and testosterone levels are at the lower end of the normal range and/or LH is in the upper normal range, a re-investigation should be offered in 1-5 years and even longer follow-up should be considered.

\section{MANAGING OF CANCER SURVIVORS WITH HYPOGONADISM}

As indicated above, men treated for different types of cancer are at increased risk of hypogonadism. Low testosterone levels may lead not only to sexual dysfunction, but also increased risk of osteoporosis as well as metabolic and cardiovascular disease. Recently it has additionally been shown that increased LH is also a risk factor of increased mortality. ${ }^{53}$ Furthermore, due to the age-dependent decrease in testosterone levels, men with isolated LH elevation may in time be at higher risk for developing manifest hypogonadism with subnormal testosterone concentration.

Evidence-based criteria for testosterone replacement therapy are lacking. Androgen replacement should be administered according to the standard guidelines. ${ }^{54,55}$ However, most guidelines recommend androgen replacement to men with total testosterone below $8 \mathrm{nmol} / \mathrm{L}$. In those with levels between 8 and $12 \mathrm{nmol} / \mathrm{L}$, hormone treatment can be considered but, based on the treatment effects, the indication for replacement therapy should be re-evaluated after 3-6 months. It should be noted that prostate cancer and breast cancer in males are contra-indications for treating with androgens, although testosterone replacement may be considered following radical prostatectomy for non-metastasing prostate cancer.

Unfortunately, sufficient evidence is lacking to show that testosterone replacement given to hypogonadal men is capable of protecting against the long-term sequelae associated with hypogonadism. ${ }^{56}$ Thus, other medical treatments and lifestyle changes eliminating or reducing risk factors of osteoporosis and metabolic as well as cardiovascular disease should be considered, even in those in whom hormone therapy has been initiated.

\section{CONFLICTS OF INTEREST}

None.

\section{REFERENCES}

1. Giwercman A, Petersen PM, 2000 Cancer and male infertility. Baillieres Best Pract Res Clin Endocrinol Metab 14: 453-471.

2. Greenfield DM, Walters SJ, Coleman RE, et al, 2007 Prevalence and consequences of androgen deficiency in young male cancer survivors in a controlled crosssectional study. J Clin Endocrinol Metab 92: 3476-3482.

3. Fung C, Fossa SD, Williams A, et al, 2015 Long-term morbidity of testicular cancer treatment. Urol Clin North Am 42: 393-408.

4. Romerius P, Stahl O, Moell C, et al, 2009 Hypogonadism risk in men treated for childhood cancer. J Clin Endocrinol Metab 94: 4180-4186.

5. Oldenburg J, 2015 Hypogonadism and fertility issues following primary treatment for testicular cancer. Urol Oncol 33: 407-412.

6. Harman SM, Metter EJ, Tobin JD, et al, 2001 Longitudinal effects of aging on serum total and free testosterone levels in healthy men. Baltimore Longitudinal Study of Aging. J Clin Endocrinol Metab 2001 86: 724-731.

7. Tajar A, Forti G, O’Neill TW, et al, 2010 Characteristics of secondary, primary, and compensated hypogonadism in aging men: evidence from the European Male Ageing Study. J Clin Endocrinol Metab 95: 1810-1818. 
8. Adler RA, 2006 Epidemiology and pathophysiology of osteoporosis in men. Curr Osteoporos Rep 4:110-115.

9. Shabsigh R, Katz M, Yan G, Makhsida N, 2005 Cardiovascular issues in hypogonadism and testosterone therapy. Am J Cardiol 96: 67M-72M.

10. Svartberg J, 2007 Epidemiology: testosterone and the metabolic syndrome. Int J Impot Res 19: 124-128.

11. Kelleher S, Conway AJ, Handelsman DJ, 2004 Blood testosterone threshold for androgen deficiency symptoms. J Clin Endocrinol Metab 89: 3813-3817.

12. English KM, Steeds RP, Jones TH, Diver MJ, Channer KS, 2000 Low-dose transdermal testosterone therapy improves angina threshold in men with chronic stable angina : a randomized, double-blind, placebo-controlled study. Circulation 102: 1906-1911.

13. Snyder PJ, Peachey H, Berlin JA, et al, 2000 Effects of testosterone replacement in hypogonadal men. J Clin Endocrinol Metab 85: 2670-2677.

14. Richiardi L, Bellocco R, Adami HO, et al, 2004 Testicular cancer incidence in eight northern European countries: secular and recent trends. Cancer Epidemiol Biomarkers Prev 13: 2157-2166.

15. Manecksha RP, Fitzpatrick JM, 2009 Epidemiology of testicular cancer. BJU Int 104: 1329-1333.

16. Stang A, Jansen L, Trabert B, et al, 2013 Survival after a diagnosis of testicular germ cell cancers in Germany and the United States, 2002-2006: a high resolution study by histology and age. Cancer Epidemiol 37: 492-497.

17. Haugnes HS, Aass N, Fossa SD, et al, 2007 Components of the metabolic syndrome in long-term survivors of testicular cancer. Ann Oncol 18: 241-248.

18. Haugnes HS, Aass N, Fossa SD, et al, 2008 Predicted cardiovascular mortality and reported cardiovascular morbidity in testicular cancer survivors. J Cancer Surviv 2: 128-137.

19. Haugnes HS, Wethal T, Aass N, et al, 2010 Cardiovascular risk factors and morbidity in long-term survivors of testicular cancer: a 20-year follow-up study. J Clin Oncol 28: 4649-4657.

20. Sprauten M, Brydoy M, Haugnes HS, et al, 2014 Longitudinal serum testosterone, luteinizing hormone, and follicle-stimulating hormone levels in a population-based sample of long-term testicular cancer survivors. J Clin Oncol 32: 571-578.

21. Skakkebaek NE, Rajpert-De Meyts E, Main KM, 2001 Testicular dysgenesis syndrome: an increasingly common developmental disorder with environmental aspects. Hum Reprod 16: 972-978.

22. Sharpe RM, Skakkebaek NE, 2008 Testicular dysgenesis syndrome: mechanistic insights and potential new downstream effects. Fertil Steril 89: 2 Suppl: e33-e38.

23. Willemse PH, Sleijfer DT, Sluiter WJ, Schraffordt Koops H, Doorenbos H, 1983 Altered Leydig cell function in patients with testicular cancer: evidence for bilateral testicular defect. Acta Endocrinol (Copenh) 102: 616-
624.

24. Petersen PM, Skakkebaek NE, Rorth M, Giwercman A, 1999 Semen quality and reproductive hormones before and after orchiectomy in men with testicular cancer. $\mathrm{J}$ Urol 161: 822-826.

25. Bandak M, Aksglaede L, Juul A, Rørth M, Daugaard G, 2011 The pituitary-Leydig cell axis before and after orchiectomy in patients with stage I testicular cancer. Eur J Cancer 47: 2585-2591.

26. Eberhard J, Stahl O, Cwikiel M, et al, 2008 Risk factors for post-treatment hypogonadism in testicular cancer patients. Eur J Endocrinol 158: 561-570.

27. Nord C, Bjoro T, Ellingsen D, et al, 2003 Gonadal hormones in long-term survivors 10 years after treatment for unilateral testicular cancer. Eur Urol 44: 322-328.

28. Petersen PM, Skakkebaek NE, Vistisen K, Rørth M, Giwercman A, 1999 Semen quality and reproductive hormones before orchiectomy in men with testicular cancer. J Clin Oncol 17: 941-947.

29. Holm M, Hoei-Hansen CE, Rajpert-De Meyts E, Skakkebaek NE, 2003 Increased risk of carcinoma in situ in patients with testicular germ cell cancer with ultrasonic microlithiasis in the contralateral testicle. J Urol 170: 1163-1167.

30. Hoei-Hansen CE, Sommer P, Meyts ER, Skakkebaek NE, 2005 A rare diagnosis: testicular dysgenesis with carcinoma in situ detected in a patient with ultrasonic microlithiasis. Asian J Androl 7: 445-447.

31. Littley MD, Shalet SM, Beardwell CG, Ahmed SR, Applegate G, Sutton ML, 1989 Hypopituitarism following external radiotherapy for pituitary tumours in adults. Q J Med 70: 145-160.

32. Buchli C, Martling A, Arver S, Holm T, 2011 Testicular function after radiotherapy for rectal cancer--a review. J Sex Med 8: 3220-3226.

33. Buchli C, Tapper J, Bottai M, et al, 2015 Testosterone and body composition in men after treatment for rectal cancer. J Sex Med 12: 774-782.

34. Kyriacou C, Kottaridis PD, Eliahoo J, et al, 2003 Germ cell damage and Leydig cell insufficiency in recipients of nonmyeloablative transplantation for haematological malignancies. Bone Marrow Transplant 31: 45-50.

35. Brämswig JH, Heimes U, Heiermann E, Schlegel W, Nieschlag E, Schellong G, 1990 The effects of different cumulative doses of chemotherapy on testicular function. Results in 75 patients treated for Hodgkin's disease during childhood or adolescence. Cancer 65: 1298-1302.

36. Vignozzi L, Corona G, Petrone L, et al, 2005 Testosterone and sexual activity. J Endocrinol Invest 28: 3 Suppl: $39-44$.

37. Wu FC, Tajar A, Beynon JM, et al, 2010 Identification of late-onset hypogonadism in middle-aged and elderly men. N Engl J Med 363: 123-135.

38. Zitzmann M, Faber S, Nieschlag E, 2006 Association 
of specific symptoms and metabolic risks with serum testosterone in older men. J Clin Endocrinol Metab 91: 4335-4343.

39. Maseroli E, Corona G, Rastrelli G, et al, 2015 Prevalence of endocrine and metabolic disorders in subjects with erectile dysfunction: a comparative study. J Sex Med 12: 956-965.

40. Corona G, Vignozzi L, Sforza A, Mannucci E, Maggi M, 2015 Obesity and late-onset hypogonadism. Mol Cell Endocrinol 418: 120-133.

41. Zarotsky V, Huang MY, Carman W, et al, 2014 Systematic literature review of the risk factors, comorbidities, and consequences of hypogonadism in men. Andrology 2: 819-834.

42. Pikwer M, Giwercman A, Bergström U, Nilsson JÅ, Jacobsson LT, Turesson C, 2014 Association between testosterone levels and risk of future rheumatoid arthritis in men: a population-based case-control study. Ann Rheum Dis 73: 573-579.

43. Maggio M, Basaria S, Ceda GP, et al, 2005 The relationship between testosterone and molecular markers of inflammation in older men. J Endocrinol Invest 28: 11 Suppl Proceedings: 116-119.

44. Bobjer J, Katrinaki M, Tsatsanis C, Lundberg Giwercman Y, Giwercman A, 2013 Negative association between testosterone concentration and inflammatory markers in young men: a nested cross-sectional study. PLoS One 8: e61466.

45. Cauley JA, 2015 Estrogen and bone health in men and women. Steroids 99: 11-15.

46. Laurent M, Antonio L, Sinnesael M, et al, 2014 Androgens and estrogens in skeletal sexual dimorphism. Asian J Androl 16: 213-222.

47. Sinnesael M, Claessens F, Boonen S, Vanderschueren D,
2013 Novel insights in the regulation and mechanism of androgen action on bone. Curr Opin Endocrinol Diabetes Obes 20: 240-244.

48. Sinnesael M, Boonen S, Claessens F, Gielen E, Vanderschueren D, 2011 Testosterone and the male skeleton: a dual mode of action. J Osteoporos 2011: 240328.

49. Gielen E, Vanderschueren D, Callewaert F, Boonen S, 2011 Osteoporosis in men. Best Pract Res Clin Endocrinol Metab 25: 321-335.

50. Morgentaler A, 2015 Testosterone deficiency and cardiovascular mortality. Asian J Androl 17: 26-31.

51. Muraleedharan V, Jones TH, 2014 Testosterone and mortality. Clin Endocrinol (Oxf) 81: 477-487.

52. Carlsen E, Olsson C, Petersen JH, Andersson AM, Skakkebaek NE, 1999 Diurnal rhythm in serum levels of inhibin B in normal men: relation to testicular steroids and gonadotropins. J Clin Endocrinol Metab 84: 1664-1669.

53. Holmboe SA, Vradi E, Kold Jensen T, et al, 2015 The association of reproductive hormone levels and allcause, cancer and cardiovascular disease mortality in men. J Clin Endocrinol Metab 100: 4472-4480.

54. Seftel AD, Kathrins M, Niederberger C, 2015 Critical update of the 2010 endocrine society clinical practice guidelines for male hypogonadism: a systematic analysis. Mayo Clin Proc 90: 1104-1115.

55. Wang C, Nieschlag E, Swerdloff R, et al, 2009 ISA, ISSAM, EAU, EAA and ASA recommendations: investigation, treatment and monitoring of late-onset hypogonadism in males. Int J Impot Res 21: 1-8.

56. Corona G, Rastrelli G, Maggi M, 2013 Diagnosis and treatment of late-onset hypogonadism: systematic review and meta-analysis of TRT outcomes. Best Pract Res Clin Endocrinol Metab 27: 557-579. 